University of Wollongong

Research Online

Faculty of Engineering and Information

Faculty of Engineering and Information

Sciences - Papers: Part A

Sciences

$1-1-2011$

\title{
Study on oxidation of stainless steels during hot rolling
}

Z Y. Jiang

University of Wollongong, jiang@uow.edu.au

D B. Wei

University of Wollongong, dwei@uow.edu.au

K Tieu

University of Wollongong, ktieu@uow.edu.au

J X. Huang

Baoshan Iron and Steel Co, Ltd

A W. Zhang

Baoshan Iron and Steel Co, Ltd

See next page for additional authors

Follow this and additional works at: https://ro.uow.edu.au/eispapers

Part of the Engineering Commons, and the Science and Technology Studies Commons

Research Online is the open access institutional repository for the University of Wollongong. For further information contact the UOW Library: research-pubs@uow.edu.au 


\title{
Study on oxidation of stainless steels during hot rolling
}

\begin{abstract}
The oxidation of stainless steels 304 and $304 \mathrm{~L}$ during hot rolling is studied in this paper. Results show the oxide scale thickness decreases significantly with an increase of reduction, and the oxide scales of both 304 and 304L stainless steels were found more deformable than the steel substrate. Surface roughness shows a complicated transfer during the hot rolling process due to the complexity of oxide scale characteristics. Also, surface roughness decreases with an increase of reduction. The friction coefficient increases with reduction in all cases, and the increase is more significant in the case of the 304 stainless steel than that of $304 \mathrm{~L}$ stainless steel.
\end{abstract}

\section{Keywords}

stainless, steels, during, study, hot, oxidation, rolling

Disciplines

Engineering | Science and Technology Studies

\section{Publication Details}

Jiang, Z. Y., Wei, D. B., Tieu, K., Huang, J. X., Zhang, A. W., Shi, X. \& Jiao, S. H. (2011). Study on oxidation of stainless steels during hot rolling. International Journal of Manufacturing, Materials and Mechanical Engineering, 1 (1), 31-42.

\section{Authors}

Z Y. Jiang, D B. Wei, K Tieu, J X. Huang, A W. Zhang, X Shi, and S H. Jiao 


\title{
Study on Oxidation of Stainless Steels During Hot Rolling
}

\author{
Z. Y. Jiang, University of Wollongong, Australia \\ D. B. Wei, University of Wollongong, Australia \\ K. Tieu, University of Wollongong, Australia \\ J. X. Huang, Baoshan Iron \& Steel Co., Ltd., China \\ A. W. Zhang, Baoshan Iron \& Steel Co., Ltd., China \\ X. Shi, Baoshan Iron \& Steel Co., Ltd., China \\ S. H. Jiao, Baoshan Iron \& Steel Co., Ltd., China
}

\begin{abstract}
The oxidation of stainless steels 304 and 304L during hot rolling is studied in this paper. Results show the oxide scale thickness decreases significantly with an increase of reduction, and the oxide scales of both 304 and 304L stainless steels were found more deformable than the steel substrate. Surface roughness shows a complicated transfer during the hot rolling process due to the complexity of oxide scale characteristics. Also, surface roughness decreases with an increase of reduction. The authors show that the friction coefficient decreases with an increase of oxide scale thickness for stainless steel 304L.
\end{abstract}

Keywords: $\quad$ Deformation, Oxidation, Oxide Scale, Stainless Steel, Surface Roughness

\section{INTRODUCTION}

The finishing temperature of hot strip rolling of stainless steels is in a range of $850-1100^{\circ} \mathrm{C}$, where there is a significant oxidation process, in which oxide scale layers are inevitably formed on the stainless steel surface. In a rolling pass, the oxide scale encounters a complicated stress state which includes: i) normal compressive pressure from the work roll; ii) shearing stress

DOI: 10.4018/ijmmme.2011010103 due to the relative speed between the oxide scale and the roll surface, and relative sliding between the oxide scale and the deforming bulk steel; iii) tension in the rolling direction due to the product elongation; and iv) bending stress when the oxide scale and the strip is deformed (Yu \& Lenard, 2002)

The deformation of oxide scale plays a key role with regard to the strip surface roughness which has an important influence on the downstream metal forming and its surface quality, especially for stainless steels. The surface of 
the oxide scale is made up of asperities, and when two surfaces are placed in contact, only the tips of the asperities touch. Forces normal to the surface make the asperities deform, and they can weld together at points of contact. Forces parallel to the surfaces are resisted by the shearing strength of these junctions. The oxide scale particles are deeply depressed into the strip surface, and the hot metal is extruded outward to fill the void between the oxide scale particles, thus generate a rougher surface (Jiang et al., 2006). At present, an increasing interest has been shown on the deformation of oxide scale during hot strip rolling (Yu \& Lenard, 2002; Munther \& Lenard, 1999; Iordanova etal., 2000; Krzyzanowski \& Beynon, 1999; Krzyzanowski et al., 2000; Krzyzanowski \& Beynon, 2002; Sun et al., 2003; Sun et al., 2004). Li et al. (2000) conducted hot "sandwich" rolling of plain carbon steel, and found that the oxide scale was strongly sensitive to the rolling temperature and reduction, and finite element modelling has been carried out to evaluate the hot ductility of the oxide scale. Suarez et al. (2009) combined previous investigations with their results, and concluded that the thin oxide scale exhibits a plastic behavior at temperatures above $900^{\circ} \mathrm{C}$, and a brittle behavior when deformed at temperatures below $700^{\circ} \mathrm{C}$, and mixed behavior was observed within this temperature range, as the oxide scale was found to resist limited amounts of deformation.

However, investigation on the deformation and surface roughness behavior of oxide scales during hot strip rolling of stainless steels is limited. Most studies on oxide scale deformation were based on carbon steel which is consisted of wustite, magnetite and hematite. While the two major potential components of a stainless steel oxide scale are the $\mathrm{M}_{2} \mathrm{O}_{3}$ rhombohedral phase and the $\mathrm{M}_{3} \mathrm{O}_{4}$ spinel phase (Mark, 2001). In this paper, the oxide scale deformation and the surface roughness transfer of 304 and 304L stainless steels are investigated. The deformation features of the stainless steel surface roughness are also discussed.

\section{EXPERIMENTAL}

An electrical furnace was adopted for reheating. Hot rolling tests were carried out on a Hille 100 Experimental Rolling Mill. A computer was used for data collection using Lab Window Software. The rolls are $225 \mathrm{~mm}$ diameter by $254 \mathrm{~mm}$ wide, induction hardened to 65 - 70RC up to $2.5 \mathrm{~mm}$ deep with an initial surface roughness of $0.4 \mu \mathrm{m}\left(\mathrm{R}_{\mathrm{a}}\right)$ (Sun, 2005). The samples after rolling were put into a cooling box connecting with nitrogen to prevent further oxidation. The surface roughness was measured by the Hommel Tester T1000, the detailed procedures can be found in (Wei et al., 2009a).

\section{RESULTS AND DISCUSSION}

\section{Deformation of Oxide Scale Under Various Reductions}

The surface morphologies of oxide scale at the lead when the reduction is from 0 to $40 \%$ were photographed, as shown in Figure 1. It can be seen that the integrality of oxide scales and the surface finish after cooling increase with an increase of reduction. When the reduction is low, the hot rolled oxide scales were inclined to break after cooling. The bonding between the remained oxide scales and steel substrate is low, and there are a lot of macro cracks. This situation is improved with an increase of reduction. When the reduction is larger than about $20 \%$, there are few macro cracks in the oxide scale, and the oxide scale is intact.

\section{Stainless Steel 304}

Figure 2 shows the microstructure of oxide scale of the 304 stainless steel under various reductions when the reheating time is $30 \mathrm{~min}$. The thickness of the oxide scale after rolling mainly depends on the reduction rather than the original thickness when the reduction is $20 \%$. The relationship between the oxide scale thickness and reduction can be found from the 
10 more pages are available in the full version of this document, which may be purchased using the "Add to Cart" button on the publisher's webpage:

www.igi-global.com/article/study-oxidation-stainless-steelsduring/51373

\section{Related Content}

Roughness Optimization of Electroless Ni-B Coatings Using Taguchi Method Suman Kalyan Das and Prasanta Sahoo (2013). Dynamic Methods and Process Advancements in Mechanical, Manufacturing, and Materials Engineering (pp. 302319).

www.irma-international.org/chapter/roughness-optimization-electrolesscoatings-using/67789/

Al2O3 Nanobricks via an Organic Free Route Using Water as Solvent M. A. Shah (2013). Dynamic Methods and Process Advancements in Mechanical, Manufacturing, and Materials Engineering (pp. 320-325).

www.irma-international.org/chapter/al2o3-nanobricks-via-organic-free/67790/

Micro Machining of Nonconductive Al2O3 Ceramic on Developed TW-ECSM Setup

Alakesh Manna and Amandeep Kundal (2013). Dynamic Methods and Process

Advancements in Mechanical, Manufacturing, and Materials Engineering (pp. 167-

177).

www.irma-international.org/chapter/micro-machining-nonconductive-al2o3ceramic/67781/

Attribute Based Selection of Thermoplastic Resin for Vacuum Infusion Process: A Decision Making Methodology

R. T. Durai Prabhakaran, Aage Lystrup and Tom Løgstrup Andersen (2013). Dynamic Methods and Process Advancements in Mechanical, Manufacturing, and Materials Engineering (pp. 267-288). www.irma-international.org/chapter/attribute-based-selection-thermoplasticresin/67787/ 
Development of an Optimization Framework for Parameter Identification and Shape Optimization Problems in Engineering

A. Andrade-Campos (2011). International Journal of Manufacturing, Materials, and Mechanical Engineering (pp. 57-79).

www.irma-international.org/article/development-optimization-frameworkparameter-identification/51375/ 